\title{
PROJETO DE ENSINO
}

\section{ENTRE LEITURAS E ESCRITAS - PORTUGUÊS PARA TODOS}

\author{
Alessandra Pereira Gomes Machado ${ }^{1}$ \\ Marlucy Mary Gama Bispo ${ }^{2}$
}

\begin{abstract}
Resumo: As dificuldades em leitura e escrita interferem no desempenho escolar, levando à retenção e abandono. Ter um diagnóstico do nível de letramento linguístico de estudantes da educação básica é o primeiro passo para pensar em estratégias efetivas para atuar nessas dificuldades que interferem no desempenho escolar. Nesse entendimento, o objetivo deste projeto é desenvolver a avaliação diagnóstica e proporcionar práticas de letramento linguístico a estudantes dos anos finais (6ㅇ a 9o ano) do Ensino Fundamental do Colégio de Aplicação da Universidade Federal de Sergipe (Codap-UFS), com a proposta de diminuir a assimetria entre nível de letramento e escolaridade discente. Para tanto, foram desenvolvidas oficinas, no turno oposto ao de aulas regulares, envolvendo graduandos dos cursos de Letras vernáculas e estrangeiras da UFS.
\end{abstract}

Palavras-chave: Língua Portuguesa. Letramento linguístico. Diagnóstico de leitura e escrita. Graduandos. Formação docente.

Introdução

O ensino e a aprendizagem da língua materna têm se constituído, ao longo dos anos, como o grande "vilão" da qualidade da educação no país. Os resultados de exames nacionais e internacionais aplicados, a exemplo do Sistema Nacional de Avaliação da Educação Básica - SAEB, Prova Brasil, Exame Nacional do Ensino Médio - ENEM, Programa internacional de avaliação de estudantes - Pisa, entre outros, a despeito de algumas críticas, têm sido desalentadores ao tempo em que desvela a aquisição da leitura e da escrita como uma problemática presente em todos os níveis da educação básica formal (BISPO, 2011).

É fato que as escolas federais tem apresentado um diferencial positivo no que se refere a tais resultados. No entanto, é fato, também, que a forma de ingresso discente, adotada por essas instituições, influenciam diretamente na performance apresentada nos rankings educacionais (BISPO, 2018). Nesses casos o filtro das provas seletivas protagoniza esse cenário de sucesso escolar.

Tomamos como exemplo o Colégio de Aplicação da Universidade Federal de Sergipe (CodapUFS), que, a partir do ano de 2010, instituiu como única forma de ingresso discente o sorteio público de vagas, em substituição ao exame seletivo através da realização de provas de Português e

\footnotetext{
${ }^{1}$ Doutora em Educação e professora de Língua Portuguesa (Colégio de Aplicação da Universidade Federal de Sergipe) alessandrasje@hotmail.com.

2 Doutora em Educação e professora de Língua Portuguesa (Colégio de Aplicação da Universidade Federal de Sergipe) marlucygama@hotmail.com.
} 
Matemática. Tal fato, comprovadamente, mudou o perfil socioeconômico e cultural dos alunos, exigindo do colégio ações diferenciadas no sentido de promover adequações institucionais e pedagógicas que viabilizassem a permanência e o sucesso do "novo" aluno.

Nesse entendimento, no caso específico do ensino de Língua Portuguesa, foram implementados pelos professores projetos de letramento, visando minimizar assimetrias existentes entre letramento linguístico e série em curso dos alunos. A última versão é o objeto apresentado neste relato.

Sobre o Colégio de Aplicação da UFS, apresentamos algumas informações que ratificam a relevância do desenvolvimento deste projeto. O Colégio tem sede no Campus da UFS, situado no município de São Cristóvão - SE, o qual, dada a sua proximidade à capital, integra a área denominada grande Aracaju. O bairro que acampa o Colégio, Rosa Elze, embora valorizado por sediar a UFS, é considerado periférico, no contexto que envolve a referida área. Atualmente o Codap-UFS oferta ensino fundamental, anos finais, e ensino médio, duas turmas por série, totalizando 420 alunos, distribuídos 30 por turmas/série. Desse quantitativo, em média 90 alunos participam do projeto. Atualmente, pós-implantação do sorteio público como forma de ingresso, o perfil socioeconômico das famílias que compõem a comunidade escolar é considerado sofrível, uma vez que $70 \%$ possui uma renda mensal entre 1 a 2 salários mínimos.

Esse "novo" contexto de situação abriga o desenvolvimento do projeto Entre leituras e escritas - português para todos, mais como uma ação afirmativa que envolve professores de Língua Portuguesa do Codap e graduandos de Letras da UFS, numa proposta clara de minimizar assimetrias existentes na relação entre nível de letramento e escolaridade discente.

\section{Pressupostos teóricos}

Partilhamos do pensamento de Bortoni-Ricardo (2006), quando defende que "o caminho para uma democracia é a distribuição justa de bens culturais, entre os quais a língua é o mais importante" (BORTONI-RICARDO 2006, p. 15). Ainda para a autora, quando alunos chegam à escola falando, por exemplo, "nós cheguemu", "abrido", e "ele drome", devemos respeitar e valorizar tais peculiaridades linguístico-culturais, mas sem negar o direito inalienável, de aprender as variantes de prestígio dessas expressões.

Entendendo que as dificuldades em leitura e escrita interferem no desempenho escolar, levando à retenção e abandono, ter um diagnóstico dos alunos do ensino fundamental no Codap-UFS é o primeiro passo para pensar em estratégias efetivas para atuar no problema dessas dificuldades. Assim, a análise descritiva do diagnóstico visa desenvolver material para a abordagem de tópicos específicos sobre língua, que costumam trazer dificuldades de leitura e escrita. 
Os resultados das avaliações em larga escala evidenciam o problema (que não estamos conseguindo resolver) da dificuldade da leitura no ensino fundamental. A porcentagem de estudantes que alcançam o nível médio de proficiência em leitura, no decorrer dos anos escolares, é um ponto inquietante a ser observado. $\mathrm{O}$ esperado era que ocorresse o contrário, quanto maior o nível de escolaridade, mais proficiência em leitura, no entanto os resultados não sinalizam para essa ampliação de proficiência; ao contrário: o déficit é cumulativo. No Codap-UFS, essa dificuldade tem se acentuado a partir da mudança da forma de ingresso de seleção para sorteio público de vagas. A dificuldade em leitura tem repercutido, também, no ensino superior. Esta dificuldade se torna mais acentuada com a recente democratização do acesso à educação superior e o ingresso de um novo perfil de aluno, formado por aqueles que tinham até então o acesso à universidade negado, a exemplo dos jovens oriundos de escolas públicas e de baixa renda, e que só após a criação das mais recentes políticas passaram a ter possibilidade de ingresso: o "novo aluno" (BRITTO et al, 2008).

Nesse contexto, torna-se necessária a promoção de políticas de permanência que possam tornar mais igualitárias as oportunidades do "novo aluno" da educação básica e do ensino superior. Não somente sob a perspectiva financeira, mas também pedagógica, uma vez que, recentemente, os discursos de que a excelência dos colégios de aplicação das IES é atribuída aos colégios que têm a seleção como forma de ingresso e de que a educação superior é deficiente, levando até à indicação de que os resultados negativos no cenário educacional são em grande parcela decorrentes das novas políticas de expansão.

Ao envolver neste projeto os graduandos do curso de Letras, majoritariamente vinculados ao perfil do "novo aluno", estamos propiciando uma formação baseada em uma pedagogia culturalmente sensível e para a pesquisa-ação, com vistas à formação profissional no campo teórico-metodológico da avaliação diagnóstica de leitura e da construção de material didático adequado às dificuldades identificadas.

A formação inicial destes graduandos, aliada à sensibilização para as questões sociais subjacentes às dificuldades em leitura e escrita coadunam com o objetivo geral do curso de Letras: "Formar profissionais interculturalmente competentes, capazes de lidar de forma crítica com as linguagens, especialmente a verbal nos contextos oral e escrito, conscientes de sua inserção na sociedade e das relações com o outro" (RESOLUÇÃO № 62/2012/CONEPE).

Considerando que a leitura envolve os processos de decodificação e compreensão, entendemos que o processo de decodificação com automaticidade (fluência em leitura oral) é basilar para a compreensão do texto lido (LABERGER, SAMUELS, 1974). Os processos de reconhecimento de letras, sílabas e palavras impressas que estão na superfície do texto são entendidos como decodificação da palavra escrita e é o modo específico de aquisição de informação (MORAIS, 1996; DEHAENE, 2012). Enquanto os processos de compreensão envolvem a utilização dessa informação 
para construir uma representação coerente com o texto escrito (SMITH, 2004; PERFETTI et al, 2013; PERFETTI; STAFURA, 2014).

\section{Metodologia}

As atividades desenvolvidas pelos participantes do projeto estão distribuídas em três momentos: as atividades de pesquisa-ação, as atividades de formação docente e as atividades de práticas do projeto, detalhadas a seguir.

\subsection{Atividades de pesquisa-ação}

A pesquisa-ação se refere a um tipo de pesquisa com base empírica que é concebida e realizada em estreita associação com uma ação ou com a resolução de um problema coletivo. Assim, nesta proposta, os professores e graduandos envolvidos no projeto participaram de atividades cooperativas e participativas (THIOLLENT, 2014).

Para o enfrentamento de uma problemática sociopedagógica complexa como a que foi apresentada, esta pesquisa-ação articulou diferentes frentes de trabalho, como pode ser visto a seguir.

\subsubsection{Diagnóstico de leitura e escrita}

O diagnóstico de leitura é um procedimento de avaliação do perfil de leitor do estudante da educação básica, que mostra o padrão de comportamento de leitura (MACHADO, 2018b). Esse diagnóstico é a base para a elaboração e planejamento de propostas pedagógicas.

Para fins deste projeto, os procedimentos de diagnóstico seguiram o estabelecido em Machado (2018b) e que consistem em:

- avaliação da fluência em leitura oral, com leitura em voz alta de texto adequado à escolaridade do estudante, seguindo o protocolo CBM (DENO, 2003), que prevê a aferição de 1 minuto de leitura e análise de processos de leitura em função de parâmetros estabelecidos em Machado (2018b);

- avaliação da produção escrita inicial, com a produção de um texto narrativo de temática adequada à escolaridade do estudante.

Os graduandos que participam do projeto de ensino foram previamente formados para atender os procedimentos da avaliação diagnóstica de leitura e escrita dos estudantes do ensino fundamental do Codap/UFS. 


\subsubsection{Análise descritiva dos processos de leitura}

A análise dos processos de leitura dos estudantes do ensino fundamental foi realizada a partir de parâmetros estabelecidos em Machado (2018b): processos de automaticidade na decodificação, de compreensão da leitura e de monitoramento da compreensão da leitura. A análise dos processos de leitura revela o perfil de leitura a partir do padrão de comportamento do leitor na leitura em voz alta. Identificar os padrões de comportamento de leitura para que se possa planejar ações pedagógicas, na perspectiva da pedagogia culturalmente sensível. Essa etapa de análise descritiva visa desenvolver material para a abordagem de tópicos específicos sobre língua, que costumam trazer dificuldades de leitura e escrita.

\subsubsection{Elaboração de material didático para oficinas de letramento linguístico}

A partir das demandas identificadas na avaliação diagnóstica, a abordagem descritiva, são previstas as seguintes ações:

- Organização e oferta de oficinas de letramento linguístico para estudantes do Codap-UFS: elaboração de material didático a partir de uma pedagogia culturalmente sensível, atendendo à avaliação diagnóstica do perfil de leitor para as oficinas de leitura, considerando as práticas de leitura na educação básica.

- Análise e discussão de dados sobre as oficinas de letramento linguístico: considerando as premissas da pesquisa-ação, os participantes avaliam a produção decorrente das oficinas ofertadas, a fim de aprimoramento e adequação de práticas, ao tempo em que são produzidos indicadores educacionais que podem auxiliar no diagnóstico de fluxo escolar, no desenvolvimento do leitor hábil (MACHADO, 2018) e na produção de protocolos de diagnóstico de leitura.

\subsection{Atividades de formação docente}

As atividades de formação profissional dos alunos de graduação envolvem:

- Participação em ciclos de estudos, seminários e demais atividades acadêmicas na área do conhecimento para aprimoramento e formação na área de atuação. Já foram desenvolvidos dois ciclos de formação: Ciclo de estudos - leitura, cognição e avaliações em larga escala e Ciclo de formação sobre leitura.

- Socialização dos resultados da pesquisa-ação em eventos científicos da área de atuação.

- Elaboração de relatórios e outros produtos científicos sobre avaliação diagnóstica de leitura e escrita no ensino fundamental e produção de material didático para as oficinas de letramento linguístico. 


\subsection{Atividades de práticas do projeto}

Por meio do diagnóstico de fluência em leitura oral (MACHADO, 2018) e de escrita, os alunos do ensino fundamental do Codap-UFS foram organizados por turma para participarem das oficinas de letramento linguístico. Estão participando do projeto 14 alunos da graduação que, após processo de formação nos ciclos de estudo, participam de atividades de planejamento das oficinas, elaboração de material didático e das oficinas de letramento linguístico.

Com intuito de desenvolver atividades de letramento linguístico que fossem significativas para os estudantes do ensino fundamental, participantes do projeto, planejamos atividades de leitura e escrita, a partir de uma única temática - o trabalho infantil: entre o legal e o real. Essas atividades, desenvolvidas nas oficinas semanais, serão apresentadas na culminância do projeto, conforme dispõe o Quadro 1.

\begin{tabular}{|c|c|c|}
\hline 6o ano & 7o ano & 8 e 9o ano \\
\hline $\begin{array}{l}\text { - convite para os pais } \\
\text { - conto } \\
\text { - jogral }\end{array}$ & $\begin{array}{l}\text { - cartaz de divulgação } \\
\text { - conto } \\
\text { - teatro }\end{array}$ & $\begin{array}{l}\text { - cerimonial no dia do evento } \\
\text { - recital: poesia e música (cordel, paródia, hip hop, } \\
\text { rap...) }\end{array}$ \\
\hline
\end{tabular}

Quadro 1 - Atividades para o encerramento das oficinas.

Importante salientar que tais atividades, além do objetivo de atender as dificuldades identificadas no diagnóstico de leitura e escrita dos alunos, servem como norte para o planejamento das referidas oficinas.

\section{Registro das oficinas}

\subsection{Planejamento}

As atividades de planejamento das oficinas ocorrem sob a orientação dos professores de Língua Portuguesa do Codap-UFS envolvidos no projeto e graduandos participantes.

O planejamento das aulas visou atender à perspectiva teórica de língua e leitura. Todas as atividades planejadas tiveram objetivos bem definidos, organizados por ordem de complexidade cognitiva dos objetivos de aprendizagem (do mais simples para o mais complexo).

Para as aulas preparadas, as atividades foram desenvolvidas verificando o tempo de execução destinado a cada tarefa.

Para o planejamento, desenvolvemos um formulário, apresentado como modelo de organização da oficina. 


\subsection{Elaboração de material didático}

O material didático para as oficinas de letramento linguístico foi construído coletivamente de forma a atender ao objetivo de desenvolver prática de leitura em voz alta e desenvolvimento de estratégias de compreensão leitora, seguidas de atividade escrita.

Todas as atividades tiveram objetivos bem definidos, organizados por ordem de complexidade cognitiva de objetivos de aprendizagem (do mais simples para o mais complexo), realizando atividades de:

1) Adaptação de texto para trabalhar em sala de aula, conforme gênero textual por nível de escolaridade:

- verificar a uniformidade de tratamento, não misturar duas pessoas do discurso. Ex.: "Ou você se atualiza ou a concorrência te engole!";

- adequar o número de palavras (trabalhar com textos curtos de 200 a 350 palavras);

- adequar o vocabulário, substituindo palavras por sinônimo adequado à escolaridade;

- adequação à temática da oficina "Trabalho infantil - entre o legal e o real";

- gênero textual adequado por série/ ano, conforme Quadro 1.

2) Sequência didática de planejamento da oficina para trabalhar leitura e escrita:

1- selecionar perguntas/questões sobre o texto para trabalhar estratégias de compreensão leitora, primeiro oralmente, e depois a parte escrita;

2- as perguntas partem de processos de leitura mais simples para o mais complexo, como:

a) localizar informações explícitas no texto;

b) Inferir informações implícitas;

c) identificar o tema;

d) relacionar informações do texto com o conhecimento prévio (por exemplo, se o aluno conhece alguém com tais características);

e) relacionar informações do texto com a temática do projeto;

f) relacionar informações com outro texto;

g) distinguir um fato da opinião relativa a esse fato.

3- contextualizar socialmente a temática trabalhada;

4- atividades de conhecimento linguístico relacionadas ao texto da aula;

5- atividade lúdica para trabalhar conhecimento linguístico.

As atividades elaboradas e desenvolvidas nas oficinas de letramento linguístico seguem os parâmetros acima relacionados. Em todas as oficinas são elaboradas atividades para produção de material para divulgação das práticas desenvolvidas de leitura e de escrita. 


\subsection{Desenvolvimento das oficinas}

As oficinas destinadas aos alunos do ensino fundamental - anos finais - são realizadas, semanalmente, em salas de aula do Codap-UFS, no turno oposto ao de aulas regulares, e coordenadas pelos professores envolvidos no projeto e pelos graduandos. A duração de cada oficina é de 1 hora e 30 minutos.

Nas fotos 1 e 2, as graduandas estão auxiliando grupos de alunos.

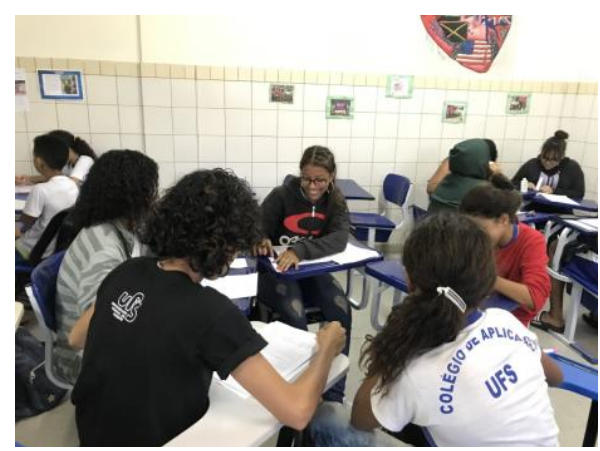

Foto 1 - Graduanda com grupo de alunos do 7으 ano

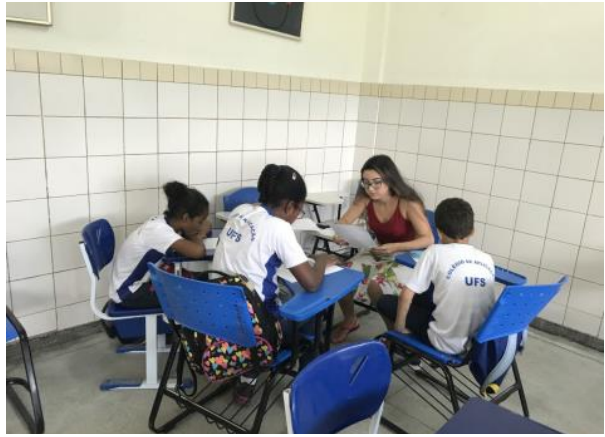

Foto 2 - Graduanda com grupo de alunos do 6으 ano

$\mathrm{Na}$ foto 3, um grupo de alunos está desenvolvendo atitude lúdica de leitura em voz alta para desenvolvimento de consciência fonológica a partir da leitura de trava-língua.

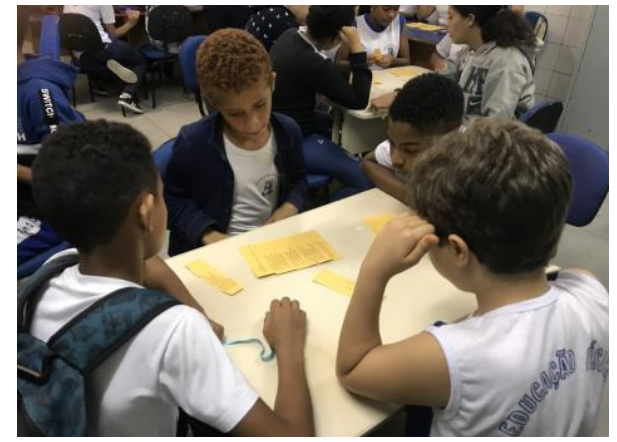

Foto 3 - Atividade lúdica de leitura em voz alta de trava-língua

Considerações finais

Apesar do projeto estar em execução até o final do ano letivo, entendemos que os resultados apresentam duas perspectivas de contribuição, a saber: i) de forma específica para o ensino de Língua Portuguesa no Codap-UFS, no sentido de garantir a inclusão e a permanência do aluno na escola e nos espaços que the são/serão abertos a partir dela; ii) de forma mais ampla, através da socialização da experiência e resultados, de forma a contribuir para o ensino de língua materna, nas redes públicas do 
ensino básico do estado de Sergipe, atendendo, assim, a uma demanda específica socialmente (im)posta, bem como a uma função específica dos colégios de aplicação brasileiros, ligados às IFES.

\title{
EDUCATION PROJECT \\ PORTUGUESE FOR ALL - BETWEEN READINGS AND WRITINGS
}

\begin{abstract}
Difficulties in reading and writing interfere with school performance, leading to retention and dropout. Having a diagnosis of the level of language literacy of students in basic education is the first step to think of effective strategies to act on these difficulties that interfere with school performance. In this understanding, the objective of this project is to provide language literacy practices to students from the final years (6th to 9th grade) of the Elementary School of the Colégio de Aplicação of the Universidade Federal de Sergipe (Codap-UFS), with the proposal of reducing the asymmetry between literacy level and student education. To this end, workshops were developed, in the opposite of the regular classes, involving college students of UFS vernacular and foreign letters courses.
\end{abstract}

Keywords: Portuguese Language. Language literacy. Reading and writing diagnosis. College Students. Teacher training.

\section{Referências}

ANDRADE, Sammela Rejane de Jesus; FREITAG, Raquel Meister Ko. Gêneros textuais e variação linguística na prova de Linguagens, Códigos e suas Tecnologias do Enem. Interfaces Científicas Educação, v. 4, p. 71-82, 2016.

ANDRADE, Sammela Rejane de Jesus. A expansão no acesso à educação superior no Brasil e a presença do novo aluno nas instituições de ensino superior. In: Anais do 10 ㅇ Encontro Internacional de Formação de Professores. Aracaju: Universidade Tiradentes, 2017, p. 1-10.

AZEVEDO, Isabel Cristina Michelan de; GASQUE, Kelley Cristine Gonçalves Dias. Contribuições dos letramentos digital e informacional na sociedade contemporânea. Transinformação, v. 29, n. 2, p. 163-173, 2017.

BISPO, Marlucy Mary Gama; Uma análise da produção textual escrita de alunos do sexto ano do ensino fundamental do Colégio de Aplicação da Universidade Federal de Sergipe. São Cristóvão: Dissertação de Mestrado. Universidade Federal de Sergipe. 2011.

BISPO, Marlucy Mary Gama; O Colégio de Aplicação da Universidade Federal de Sergipe: entre excelência e referência. São Cristóvão: Tese de Doutorado. Universidade Federal de Sergipe. 2018.

BRITTO, Luiz Percival Leme. SILVA, Edineuza Oliveira. CASTILHO, Katlin Cristina de. ABREU, Tatiane Maria. Conhecimento e formação nas IES periféricas: perfil do aluno "novo" da educação superior. Avaliação: Revista de avaliação do Ensino Superior, v.13, n. 3, p. 777-791, 2008.

FREITAG, Raquel Meister Ko. A nota do Enem: acesso e permanência na Universidade Federal de Sergipe In: (Re) pensando as licenciaturas. São Cristóvão: EdUFS, 2016, p. 75-90. 
FREITAG, Raquel Meister Ko. Documentação Sociolinguística, coleta de dados e ética em pesquisa. São Cristóvão: EdUFS, 2017a.

FREITAG, Raquel Meister Ko. Falares Sergipanos. In: ATAÍDE, Cleber. et alii. Gelne 40 anos: experiências teóricas e práticas nas pesquisas em linguísticas e literatura. São Paulo: Blucher, 2017b, p. $119-130$.

LABERGE, David; SAMUELS, S. Jay. Toward a theory of automatic information processing in reading. Cognitive psychology, v. 6, n. 2, p. 293-323, 1974.

MACHADO, Alessandra Pereira Gomes. PROVA BRASIL: UMA LEITURA DA AVALIAÇÃo. Encontro Internacional de Formação de Professores e Fórum Permanente de Inovação Educacional, v. 10, n. 1, 2017.

MACHADO, Alessandra Pereira Gomes. Variação linguística e leitura: fenômenos variáveis da fala na leitura em voz alta. A Cor das Letras, v. 19, n. 4Especial, p. 196-218, 2018a.

MACHADO, Alessandra Pereira Gomes. Fluência em leitura oral e proficiência em leitura: automaticidade na decodificação para a compreensão leitora. 2018. Tese (Doutorado em Educação). Universidade Federal de Sergipe, 2018b.

THIOLLENT, M. Pesquisa participante e pesquisa-ação: Uma visão de conjunto. In: STRECK, Danilo; SOBOTTKA, Emil A.; EGGERT, Edla. (Org.). Conhecer e Transformar: Pesquisa-ação e pesquisa participante em diálogo internacional. Curitiba: Editora CRV, 2014. p. 15-26. 